\title{
CORRESPONDENCE
}

We welcome letters to the Editor concerning articles which have recently been published. Such letters will be subject to the usual stages of selection and editing; where appropriate the authors of the original article will be offered the opportunity to reply.

Letters should normally be under $\mathbf{5 0 0}$ words in length, double-spaced throughout, signed by all authors and fully referenced. The edited version will be returned for approval before publication.

\section{USE OF TOURNIQUETS}

Sir,

I would like to comment on the paper in your January issue entitled 'The use of a tourniquet when plating tibial fractures' by Salam et al (1991; 73-B:86-7). The authors reported 60 patients with closed tibial fractures who underwent open reduction and internal fixation with $A O$ plates and screws. Half of the operations were performed with a thigh tourniquet and half without. In the tourniquet group there were six cases with erythema and induration of the wound and in the other group there were no such complications.

The authors state that the bloodless field achieved by a tourniquet may predispose to a low-grade infection. However, this conclusion is not supported by the information supplied in the paper. Bacterial cultures were sterile in all of the patients, who were also apyrexial, and had normal white cell counts and blood sedimentation rates. In these circumstances it is not possible to state that there was an infection, and all that can be said is that there were minor problems with wound healing possibly related to haematoma formation.

The patients were randomly allocated to two treatment groups, but the authors do not state who carried out the postoperative assessment; if there were different observers, they could have used differing criteria. It would have been preferable to have had only one observer who did not know whether a tourniquet had been used or not.

In my opinion, there does not appear to be any scientific foundation for the conclusions in this paper.

M. J. MCMASTER, MD, FRCS

Consultant Orthopaedic Surgeon,

Princess Margaret Rose Orthopaedic Hospital,

Fairmilehead,

Edinburgh EH10 7ED,

Scotland.

Salam AA, Eyres KS, Cleary J, El-Sayed HH. The use of a tourniquet when plating tibial fractures. J Bone Joint Surg [Br] 1991 ; 73-B:86-7.

\section{Reply from the authors:}

Sir,

May we reply to the comments made by Mr M. J. McMaster?

We would like to reiterate that in none of the six patients who developed skin changes suggestive of infection were we able to identify an infective cause. We stated this clearly in the paper and suggested that the tourniquet may produce induration and erythema and predispose to low-grade,

(C) 1991 British Editorial Society of Bone and Joint Surgery 0301-620X/91/5271 \$2.00

J Bone Joint Surg [ Br] 1991 ; 73-B :869-70. secondary infection. These inflammatory, rather than infective, changes in the soft tissues were not seen in the nontourniquet group.

The other point concerned the postoperative assessment. All the surgery was performed by AAS, and the subsequent assessment of all cases was by KSE who was at that time independent of the operating hospital.

We would like to thank $\mathrm{Mr}$ McMaster for his interest and hope that our comments will clarify the situation.

A. A. SALAM, FRCS

Department of Orthopaedics,

Wrexham Maelor Hospital,

Wrexham,

Clwyd LL3 7TD,

Wales.

J. CLEARY, FRCS

K. S. EYRES, FRCS

Department of Orthopaedics,

Huddersfield Royal Infirmary,

Acre Street,

Lindley,

Huddersfield HD3 3EA,

England.

\section{TAKING A BONE GRAFT}

Sir,

I refer to the brief report on 'A quick method of taking a bone graft' by Graham, Dent and Jones published in your January issue (1991; 73-B:179). The method that they describe has been used for many years by Swiss orthopaedic surgeons and published (Dick 1986, 1987). This prior publication should be recorded in your journal.

E. VAN HOLSBEECK, MD

Orthopaedic Surgeon,

Muylemstraat 146,

9498 Ninove-Appelterre,

Belgium.

Dick W. Use of the acetabular reamer to harvest autogeneic bone graft material: a simple method for producing bone paste. Arch Orthop Trauma Surg 1986; 105:235-38.

Dick $W$. The 'fixateur interne' as a versatile implant for spine surgery. Spine 1987; 12:882-900.

Graham GP, Dent CM, Jones DG. A quick method of taking a bone graft. J Bone Joint Surg [Br] 1991; 73-B:179.

Sir,

I would like to comment on the paper by Graham et al (1991) regarding the power-reaming technique of harvesting iliac bone grafts and reporting it as being "without complications".

This method has been used in Canada for at least a 